\title{
IMPLEMENTATION OF GEOGRAPHIC INFORMATION SYSTEM IN MILITARY TERRAIN ASSESSMENT
}

\author{
Bojan Cvijanović, Marko Pavlović and Lazar Tomašević \\ Ministry of Defense of Bosnia and Herzegovina
}

Geographic Information System ${ }^{1}$ has made a great leap in the last

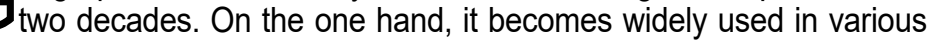
fields of the society. On the other hand, terrain plays significant role in the military activities of all kinds. It must be accounted for during planning and preparation of military operations. This article explores application of GIS in military terrain assessment. The proper Intelligence Preparation of the Battle space ${ }^{2}$ in the real situation would require taking into consideration many factors including terrain, weather, population, enemy, etc. However, the focus of this work is on plain terrain analysis with the aim to examine one. For this purpose, a Model in ArcGIS Desktop Model Builder has been made, which results in raster showing several classes of terrain. The method used in the analysis is a Weighted Suitability Analysis ${ }^{3}$. The results of WSA indicate that the terrain in the area of interest is favorable for movement of up to one mechanized division. Definition and classification to define terms and recognized interaction among them has been used.

Key Words: GIS, ArcGIS, terrain analysis, IPB, military application

\section{Introduction}

Terrain analysis is of crucial importance for success on the battlefield. The knowledge of enemy's doctrine, Tactics, Techniques and Procedures ${ }^{4}$ and capabilities complemented by adequate terrain assessment is a precognition for recognizing its intentions in the area. In the US Army Field Manual 34-130 Intelligence Preparation of the Battlefield ${ }^{5}$ it is recommended that these factors should be considered during terrain analysis: Cross-country mobility; Transportation systems (road and bridge information); Vegetation type and distribution; Surface drainage and configuration; Surface materials (soils); Ground water; and Obstacles.

\footnotetext{
${ }^{1}$ The abbreviation GIS will be used further in the text.

${ }^{2}$ The abbreviation IPB will be used further in the text.

${ }^{3}$ The abbreviation WSA will be used further in the text.

${ }^{4}$ The abbreviation TTPs will be used further in the text.

${ }^{5}$ Field Manual 34-130, "Intelligence Preparation of the Battlefield", Department of the Army, Washington DC, 1994 , p. 2-9.
} 
Implementation of Geographic Information System in Military Terrain Assessment

Analysis of military aspects of terrain in staff work has been done manually until recently. The development of different GIS software has enabled its military application. There are several tools for military use developed by Esri, which are based on ArcGIS software. In this project ArcGIS Desktop 10.3.1. with a Student Advanced License has been used. The model which processes data and analyze(s) terrain has been built in the ArcGIS Desktop Model Builder. The model includes all abovementioned factors, it converts features into raster and as a result it calculates suitability of terrain for movement of mechanized units.

During preparation of data the appropriate value has been assigned to each data set with regard to its negative or positive influence on the movement of troops across the terrain. The military classification has been used including:

- "Unrestricted" - terrain does not hamper the movement of units (no steep slopes, land type favors units movement, no forests, etc.),

- "Restricted" - terrain moderately hampers the movement of units, it canalizes its movement through corridors, units have to avoid obstacles, etc.,

- "Severely Restricted" - terrain significantly hampers the movement of units, making it impassable without great effort, use of special equipment and great loss of time.

Those values are in the range from one to three respectively $(1-$ does not restrict movement significantly, 2 - restricts movement significantly and 3 - severely restricts movement making it impassable without special equipment) for negative influence features, and values of -1 or -2 for features that enhance mobility. To be more precise, if there is a forest the value of 3 has been assigned to it because it hampers the movement of units, particularly motorized, or, on the other hand, if there is a road the value of -1 or -2 has been assigned to it because it has positive influence on the movement of units. All but DEM layer has originally been polygon or line feature. Those layers have to be converted to raster and afterwards Raster Calculator has to be used to replace Null values with zeros.

The last step in the Model that has been made is WSA. The "relative importance" has been assigned to all layers based on an analyst personal opinion. This part of analysis depends largely on the experience of an analyst and their military knowledge.

\section{GIS in Military Terrain Assessment}

The rapid development of Information Technology in the last quarter of $20^{\text {th }}$ and the first quarter of $21^{\text {st }}$ century has led to the increased implementation of GIS Technology in the armies of the developed countries. To understand how GIS can be utilized in IPB process and, more precisely, in the terrain assessment, it has to be defined what GIS and Military Terrain Assessment actually are.

\section{Geographic Information System}

From the ancient times, terrain has played major role in various human activities. People live in space and they are surrounded with different things in space. It is the factor which has influenced human behavior and which has to be accounted for when making decisions on where to build a settlement, where to cross the river, or, in the military sense, what the best place for engaging enemy is. 
In some sense, the roots of GIS can be found in the process of making static paper maps. The process itself was slow and hard, requiring collection of spatial information "on foot" and drawing different layers one on the top of the other manually. In the beginning, the main function of collection of spatial data was actually to show where things are and how they are located in relation to each other. This is called cartography.

However, apart from cartography function, the significant part of modern GIS is spatial analysis capability. In relation to this, the first recorded and maybe the most known example of spatial analysis is the case of John Snow's London cholera analysis. John Snow was an English physician famous for his analysis of cholera outbreak in London in 1854. He used a simple map with streets of London and water pump locations. He put all the cholera cases on the map and as a result he concluded that most of the cases were in the vicinity of one of water pumps. On the basis of this, he concluded that the pump was source of disease. When people stopped taking water from that pump, the disease slowly ended.

This example, despite being done using primitive means, shows the way how spatial analysis, in this case overlay of different layers, could contribute in solving real life problems. Today, there are numbers of spatial analysis techniques. Seven basic spatial analysis techniques are: Selection, Buffering, Dissolve, Overlay Operations, Classification, Table Operations and Geocoding ${ }^{6}$. We will not discuss these techniques in depth in this article; however, it is important to stress the importance of GIS and its wide spectra of application in various fields of the modern world.

Still, we cannot speak of GIS until modern computers appeared in the mid-20 ${ }^{\text {th }}$ century. The development of modern computer devices and specially their availability to a wide auditorium of users enabled the birth and evolution of GIS. Today, the world would hardly be imaginable without GIS; think of software applications such as Google maps, Open Street Maps, different types of applications for navigation, all the way to professional proprietary GIS software such as ArcGIS, or the free ones such as QGIS.

There are many definitions of GIS but, basically, it is "an organized system of hardware, software, data, trained personnel and network with the aim to effectively collect, store, update, manage, analyze, model, transfer and display all types of spatial information". ${ }^{7}$

It is useful to view GIS as a process rather than a thing. ${ }^{8}$ It is a combination of:

a. Hardware - refers to all necessary equipment for GIS use such as computers, plotters, digitizers, etc.

b. GIS software - enables manipulation of spatial data depending on its capabilities, e.g. spatial analysis, cartography, routing, etc.

c. Spatial data - refers to any data which has spatial component. According to some sources, $80 \%$ of all data has been somehow spatially determined.

d. Trained personnel - makes crucial part of GIS. The more trained users the more benefit they will be able to gain from the system.

e. Lastly, there is a network - which can be seen as computer network (e.g. Internet) and people network.

\footnotetext{
${ }^{6}$ CN-1681-INTRO-QGIS, "Introduction to Geospatial Technology Using QGIS", Canvas MOOC, 2015.

${ }^{7}$ Verka Jovanović, "Geografski informacioni sistemi, Prvo izdanje", Univerzitet Singidunum Beograd i Univerzitet u Novom Sadu, Beograd, 2012, p. 11.

${ }^{8}$ Script, "Reference systems and cartographic representations", Geo Cell, EUFOR, 2008, p. 26.
} 
GIS has found its application in many fields, e.g. urban planning, agronomy, transportation, education, navigation, etc. GIS can aid and make easier the execution of military tasks. It can be used to produce terrain analysis products such as: modified combined obstacle overlays, hydrology overlays, slope maps, on and off road mobility maps, line-of-sight plots, concealment maps, possible problems associated with lines of communications, etc. ${ }^{9}$

Every GIS contains subsystems for:

- data input,

- data storage, retrieval and representation,

- data management, transformation and analysis,

- data reporting and product generation. ${ }^{10}$

The company with greatest share in the market concerning GIS technology is Esri. Its ArcGIS product has set standards and is regarded as one of the best proprietary software in the field. The system provides infrastructure for making maps and geographic information available throughout an organization, across a community, and openly on the Web. ${ }^{11}$ ArcGIS Desktop, which has been used in this project, has several parts such as ArcMap, ArcCatalog, ArcScene, ArcGlobe, etc. There are three functionality levels, which depend on available licenses:

- ArcGIS for Desktop Basic, which allows one to view spatial data, create layered maps, and perform basic spatial analysis;

- ArcGIS for Desktop Standard, which in addition to the functionality of Basic, includes more advanced tools for manipulation of shape files and geo-data bases;

- ArcGIS for Desktop Advanced, which includes capabilities for data manipulation, editing, and analysis. ${ }^{12}$

\section{Mission Terrain Analysis}

Terms

All the most important military theorists of the world have written about the significance of the terrain during the warfare. A terrain analysis in war theory literature occupies a very important place.

Sun Tzu, famous Chinese war theorist, recognized five factors of war. Among moral, weather, command and doctrine, on the third place we could find terrain. He states: "By terrain I mean distances, whether the ground is traversed with ease or difficulty, whether it is open or constricted, and the chances of life or death". ${ }^{13}$ Also, he wrote a chapter about terrain consideration.

Carl von Clausewitz in his work "On War" considers three properties through which the ground has an influence on action in war; that is, as presenting an obstacle to approach, as an obstacle to an extensive view, and as protection against the effect of fire-arms; all other

\footnotetext{
${ }^{9}$ Ibid.

${ }^{10}$ Ibid.

${ }^{11} \mathrm{https} / / /$ en.wikipedia.org/wiki/ArcGIS\#cite_note-65, accessed on 13th June 2017. at 11:39 CEST.

${ }^{12}$ https://en.wikipedia.org/wiki/ArcGIS\#cite_note-65, accessed on 13th June 2017. at 11:50 CEST.

${ }^{13}$ Sun Tzu, "The Art of War", Oxford University Press, New York and Oxford, p.64.
} 
effects may be traced back to these three. He further says: "each of these three kinds of ground in proportion as its own special peculiarity has a tendency to an extreme, has in the same degree a tendency to lower the influence of the supreme command, increasing in like manner the independent action of subordinates down to the private soldier". ${ }^{14}$ Also, he distinguishes three types of terrain: level plain country, thickly-wooded country and mountains. It was found out that each of these three kinds of ground has an effect in its own way on movement, the range of sight, and the cover it affords.

Frederick II the Great in his "Universal War Principles - Instructions to generals"15 emphasizes: "For a general, the knowledge of land is the same as a gun to an infantry soldier or an arithmetic rule to a mathematician. If he does not know the land, all the time he will make gross mistakes." ${ }^{16} \mathrm{He}$ continued: "Without this knowledge, a commander's plans become ridiculous and unfeasible". Therefore, Frederick II warns: "Study the land on which you will act!" ${ }^{17}$

Terrain is usually defined as a stretch of land, especially with regard to its physical features. ${ }^{18}$ Also, it is described as a geographic area or a piece of land ${ }^{19}$. Finally, terrain is exemplified as a tract of land, especially considered with reference to its natural features, military advantages, etc. ${ }^{20}$ The origin of term terrain is from French, actually from a popular Latin variant of Latin terrenum, terra which means earth, and dates to the early 18th century. In some way the synonyms in the English language are ground or field. However, in the military sense there are differences. A field is defined as "area where a battle or other military operation takes place". ${ }^{21}$ It is the synonym to the term battlefield "the ground on which a battle is fought". ${ }^{22}$ Also, in recent years the term battlespace is in use in military terminology. It is defined as "The environment, factors, and conditions that must be understood to successfully apply combat power, protect the force, or complete the mission. This includes air, land, sea, space, and the included enemy and friendly forces; facilities; weather; terrain; the electromagnetic spectrum; and the information environment within the operational areas and areas of interest". ${ }^{23}$

\section{Terrain analysis process}

Proper terrain analysis is as essential to success on the battlefield today as it was during the ancient and medieval times. The knowledge of the environment is a precondition for making a good decision during a war. Throughout Military Decision Making Proc-

\footnotetext{
${ }^{14}$ Carl von Clausewitz, "On War", trans. COL James John Graham, N. Trübner, London 1873, Book 5, Chapter 17 On Country and Ground.

${ }^{15}$ Original title: "Fridrich II der Grosse, Les Principes Generaux de la Guerre"

${ }^{16}$ Group of autors, "Rasprave o ratnoj veštini", VINC, Beograd, 1991, p. 291.

${ }^{17}$ Ibid.

${ }^{18} \mathrm{https} / / /$ en.oxforddictionaries.com/definition/terrain, accessed on 27th June2017.

${ }^{19} \mathrm{https}: / / \mathrm{www}$.merriam-webster.com/dictionary/terrain, accessed on 27th June 2017.

${ }^{20} \mathrm{http}: / /$ www.dictionary.com/browse/terrain, accessed on 27th June 2017.

${ }^{21}$ Richard Bowyer, "Dictionary of Military Terms", third edition, A\&C Black, London, p.93.

${ }^{22}$ Richard Bowyer, "Dictionary of Military Terms", third edition, A\&C Black, London, p.25.

${ }^{23}$ FM 1-02, "Operational Terms and Graphics", Headquarters Department of the Army, Washington DC, 2004, p.1-21.
} 
Implementation of Geographic Information System in Military Terrain Assessment

ess, ${ }^{24}$ intelligence elements have the task to collect and disseminate relevant products (data, information and intelligence) about environment to decision makers at all levels of command and control. Due to this, they complete intelligence preparation of the battlefield or battlespace ${ }^{25}$ to fill "intelligence gaps" of decision makers. IPB is "a systematic process of analyzing and visualizing the portions of the mission variables of threat or adversary, terrain, weather, and civil considerations in a specific area of interest and for a specific mission". ${ }^{26}$ As it is known, an IPB process consists of four steps: Define the operational environment; Describe environmental effects on operations; Evaluate the threat/adversary; and Determine threat/adversary courses of action.

In the second step of IPB, "Describe environmental effects on operations", intelligence officers have to evaluate how the environment/battlespace area of interest affects and influences both threat/adversary and friendly operations. The aim of the process is that decision-makers understand advantages and disadvantages of threat or adversary, terrain, weather and other factors and exploit them in a correct way to achieve success.

In this paper, only a terrain analysis will be considered. It is defined as "the study and interpretation of natural and man-made features of an area, their effects on military operations, and the effects of weather and climate on these features". ${ }^{27}$

During analysis of terrain, there are some guidelines we should follow:

- Due to changes in terrain, we have to update our analysis. Thus, terrain analysis is a continuous process.

- The study of a map or image should not be the only source for analysis. Indeed, it will help to identify gaps in knowledge of terrain.

- Terrain analysis should be based on reconnaissance of the area of operations and area of interest. This largely depends on the available time.

According to FM 2-01.3, ${ }^{28}$ conclusions about the effects of terrain are reached through two sub steps:

- Analyze the military aspects of terrain.

- Evaluate terrain's effect on military operations.

After identifying area of operations and area of interest, a terrain analysis mainly focuses on the military aspects of terrain. It consists of: observation and fields of fire, avenues of approach, key and decisive terrain, ${ }^{29}$ obstacles, and cover and concealment ${ }^{30}$. These are general guidelines when analyzing and defining the battlefield rather than strict ones. Also, the influence and effects of weather on terrain have to be considered if we want an excellent conclusion about terrain.

\footnotetext{
${ }^{24}$ Heareinafter abbreviated MDMP.

${ }^{25}$ Heareinafter abbreviated IPB.

${ }^{26}$ FM 2-01.3,MCRP 2-3A, "Intelligence Preparation of the Battlefield/Battlespace", Headquarters Department of the Army, Washington DC, October 2009, p.1-1.

${ }^{27}$ FM 34-3, "Intelligence Analysis", Headquarters Department of the Army, Washington DC, July 2009, p. 3-14.

${ }^{28}$ FM 2-01.3,MCRP 2-3A, "Intelligence Preparation of the Battlefield/Battlespace", Headquarters Department of the Army, Washington DC, October 2009, p. 3-3.

${ }^{29}$ Key Terrain: „Any location or area which the seizure, retention or control of affords a marked advantage to either combatant." Decisive Terrain: „Key terrain which the seizure, retention or control of is necessary for mission accomplishment."https://www.flashcardmachine.com/maneuver-captains-course.html, accessed on 6th July 2017. at 10:45 CEST.

${ }^{30}$ Hereinafter abbreviated OAKOC.
} 
After this, an intelligence analyst has to consider terrain's effects on available threat/adversary COAs and friendly forces COAs. They have to focus on the military aspects of terrain in great detail. "There are four basic techniques to evaluate terrain's effects on COAs: Concentric ring, Belt, Avenue in depth and Box." ${ }^{31}$

It could be concluded that a terrain analysis is continuous process and very important part of IPB and MDMP.

\section{Terrain analysis importance}

Staff planners, who realize the importance of a terrain analysis and are equipped with the proper tools, are key planners of a successful operation. If they are skilled at their tasks, they can fully determine limitations and possibilities in an area of operations. For instance, an attack will be directed toward areas where the enemy is the weakest and where terrain favors strengths of its own forces the most. According to the needs in a battlespace, most staff planners at a brigade level and below, particularly an intelligence officer, assistant brigade engineer and task force engineer, realize the significant role they have in conducting terrain analysis tasks in support of operations planning. Contemporary planners use modern automated tools and equipment to carry out very detailed analyses of terrain and weather. The utility and availability of these tools continue to increase, and they provide timely support to planners.

The geospatial engineer elements and teams provide support to the G-2/S-2, and also the direct support to a unit. Nowadays, computers and programs enable generation of a terrain model and its display into two-dimensional or three-dimensional view. Of course, leaders and commandants should always carry out a physical reconnaissance of terrain when it is possible.

\section{Methods}

The main method that has been used in the project is Weighted Suitability Analysis. As a guide for this project the US Army FM 2-01.3 has been used. Terrain analysis has been a part of Intelligence Preparation of Battlefield process. The factors that should be considered are:

- Cross-country mobility,

- Transportation systems (road and bridge information),

- Vegetation type and distribution,

- Surface drainage and configuration,

- Surface materials (soils),

- Ground water,

- Obstacles.

${ }^{31}$ FM 2-01.3,MCRP 2-3A, "Intelligence Preparation of the Battlefield/Battlespace", Headquarters Department of the Army, Washington DC, October 2009, p. 3-8. 
The data, which has been used for the project was downloaded from the Internet. It has been decided to use open source data with the aim to demonstrate an approach of using GIS for military purpose wittingly, disregarding reliability and accuracy of data. A data set has been downloaded as follows:

- Roads - line features,

- Railroads - line features,

- Small rivers - line features,

- Major rivers - polygon features,

- Forests - polygon features,

- Land use - polygon features,

- Lakes - polygon features,

- Swamps - polygon features,

- Built - up areas - polygon features, and

- DEM - raster.

In addition to the abovementioned data sets, the authors considered some other data such as airports, power lines, etc. which would be important for assessing an area of operations in reality. However, it has been decided to stick to the abovementioned just to keep the project feasible in the given time and space.

After obtaining the data, the authors have examined all the data and found out what it consists of. Some pre-processing and adjustment of the data had to be done in order to allow the use of the data for the specific purpose of this project. The field „weight" has been added into attribute tables of each feature of a data set and it has been filled in accordance with the way they influence movement in the area. For example, obstacles such as Forests, Lakes, Major Rivers, Swamps, etc. have been weighted as value of 3 (it hampers movement significantly); Small Rivers have been weighted as value of 2 (they hamper movement moderately) and Roads and Railways have been weighted as value of 1 or 2 (they enhance mobility).

The authors have decided to do Suitability Analysis and make a Model including all abovementioned data. Firstly, all feature layers had to be converted to raster in order to allow their use in the tool Weighted Overlay. In order to avoid Null values, all of them were converted into zeros. Secondly, DEM has been used to calculate slopes. Slope layer has been taken and reclassified as follows:

$-<30$ - unrestricted,

- 30-45 - restricted, and

$->45$ severely restricted terrain. ${ }^{32}$

When it comes to the last step in the process, which is Weighted Analysis, the authors had to rely on the US Army FM 2-01.3., and their personal judgment to decide what importance each of the abovementioned factors has on the movement of mechanized units.

\footnotetext{
${ }^{32}$ Numbers represent slope in percent.
} 


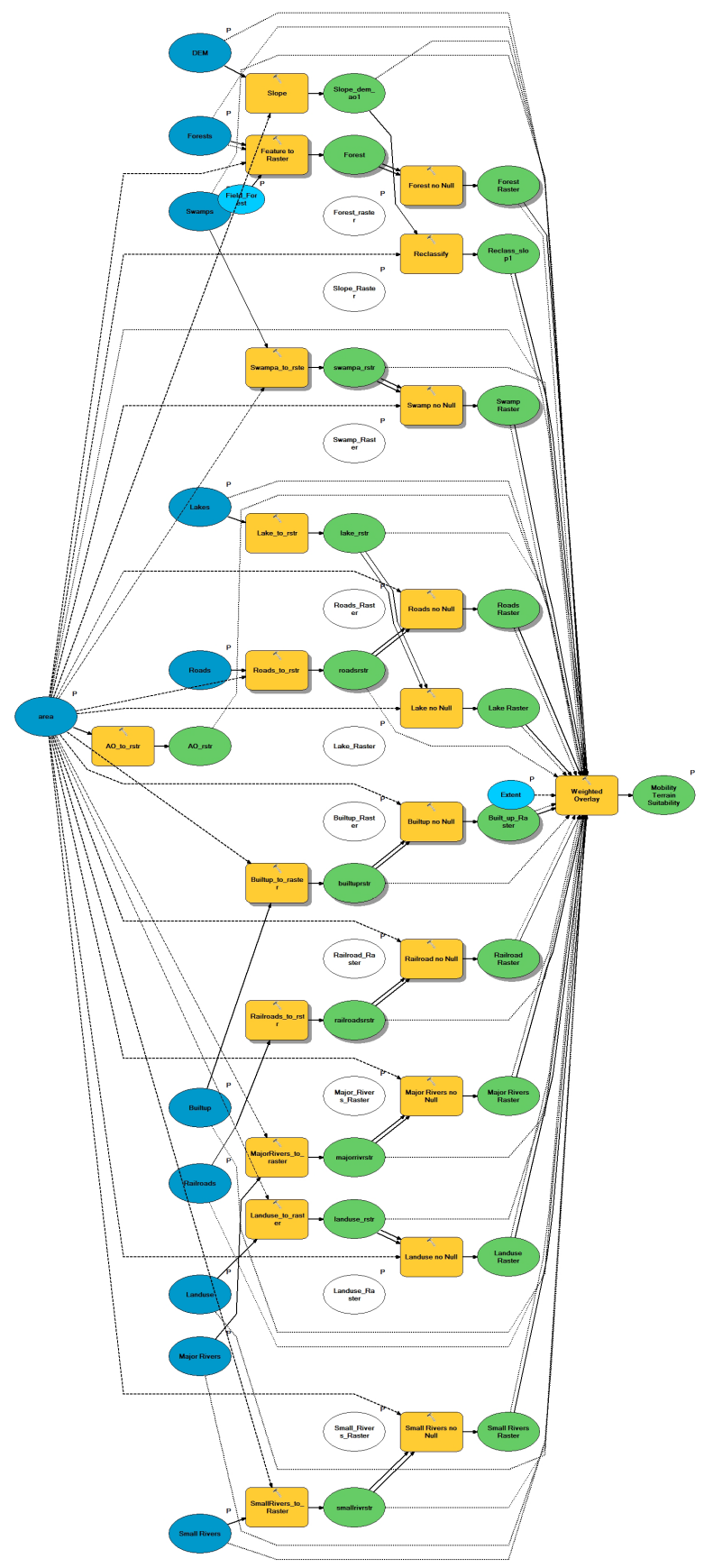


Legend:

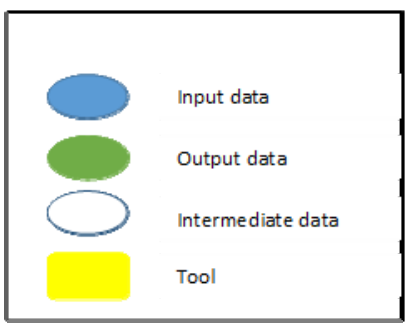

Fig. 1 - Model Builder Scheme

When deciding how to measure influence of each of the factors, a number of features have been taken into consideration in this particular area (for example, there are not too many lakes and therefore we consider them moderately important). The values in the weighted overlay table from the tool can be seen below.

Table 1 - Weighted overlay table

\begin{tabular}{|c|c|c|c|}
\hline Raster & Influence $\%$ & Field & Scale value \\
\hline Reclassified Slope Raster & 20 & $\begin{array}{c}1 \\
2 \\
3 \\
\text { NODATA }\end{array}$ & $\begin{array}{c}5 \\
3 \\
1 \\
\text { NODATA }\end{array}$ \\
\hline Major Rivers Raster & 10 & $\begin{array}{c}0 \\
3 \\
\text { NODATA }\end{array}$ & $\begin{array}{c}5 \\
1 \\
\text { NODATA }\end{array}$ \\
\hline Small Rivers Raster & 5 & $\begin{array}{c}0 \\
2 \\
3 \\
\text { NODATA }\end{array}$ & $\begin{array}{c}5 \\
3 \\
1 \\
\text { NODATA }\end{array}$ \\
\hline Forest Raster & 10 & $\begin{array}{c}0 \\
3 \\
\text { NODATA }\end{array}$ & $\begin{array}{c}5 \\
1 \\
\text { NODATA }\end{array}$ \\
\hline Roads Raster & 20 & $\begin{array}{c}-2 \\
-1 \\
0 \\
\text { NODATA }\end{array}$ & $\begin{array}{c}5 \\
5 \\
1 \\
\text { NODATA }\end{array}$ \\
\hline Lake Raster & 5 & $\begin{array}{c}0 \\
3 \\
\text { NODATA }\end{array}$ & $\begin{array}{c}5 \\
1 \\
\text { NODATA } \\
\end{array}$ \\
\hline Swamp Raster & 5 & $\begin{array}{c}0 \\
3 \\
\text { NODATA }\end{array}$ & $\begin{array}{c}5 \\
1 \\
\text { NODATA }\end{array}$ \\
\hline
\end{tabular}




\begin{tabular}{|c|c|c|c|}
\hline Raster & Influence\% & Field & Scale value \\
\hline Railroad Raster & 5 & -1 & 5 \\
& & 0 & 1 \\
& & NODATA & NODATA \\
\hline Built up Raster & 10 & 0 & 5 \\
& & 3 & 1 \\
& 10 & NODATA & NODATA \\
\hline Land use Raster & & 0 & 5 \\
& & 1 & 5 \\
& & 3 & 3 \\
& & NODATA & 1 \\
& & & NODATA \\
\hline
\end{tabular}

\section{Results}

As a result of Weighted Analysis, which has been done with these inputs and settings, and after symbolizing in three classes - Natural Jenks method - the result is the raster that shows which routes mechanized units from the town of Prijedor could take to reach Banja Luka. On the basis of the product of the tool, it is possible to assess where Mobility Corridors and Avenues of Approach, Key terrain, and main obstacles are.

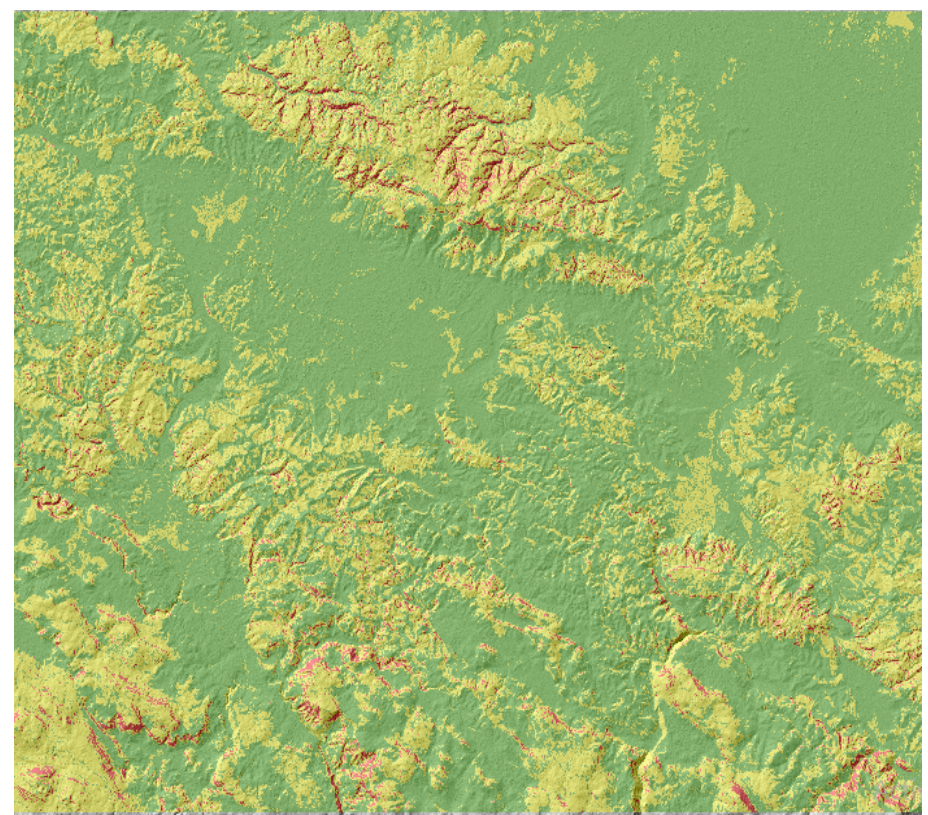

Picture 1 - Suitability of terrain for movement of mechanized units 
Three classes have been shown: green for unrestricted, yellow for restricted and red for severely restricted terrain. Also, in the picture 2, additional information has been included such as boundaries of possible Area of operations of a hypothetical enemy, boundaries of the cities of Banja Luka and Prijedor, roads, rivers, etc. which have only been included for easier understanding.

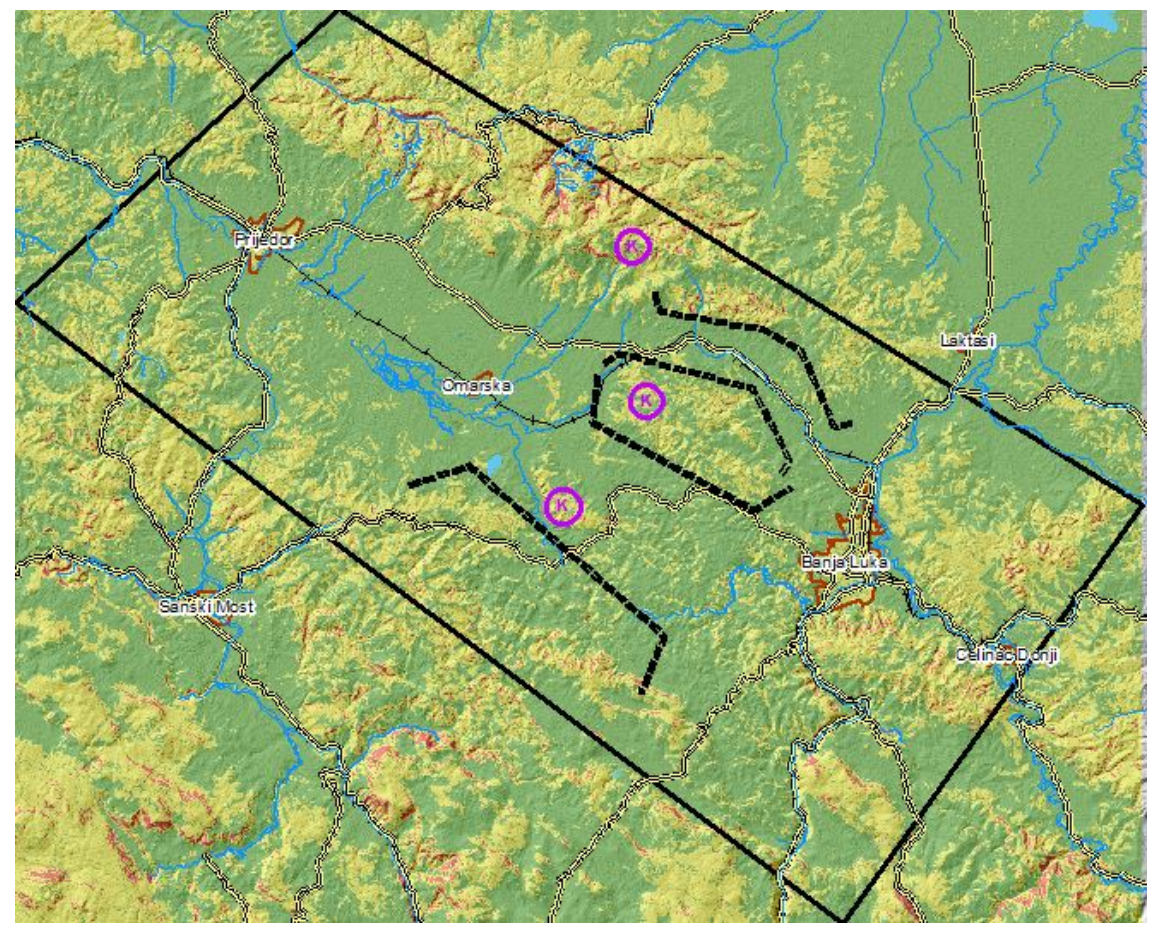

Picture 2 - Suitability of terrain for movement of mechanized units with additional explanation

\section{Discussion and conclusion}

The resulting raster shows that the terrain between Prijedor and Banja Luka is mainly suitable for movement of mechanized units. There is $17 \mathrm{~km}$ wide flat ground between the two cities. There are no major obstacles when advancing Prijedor until $16 \mathrm{~km}$ before Banja Luka. In front of Banja Luka from the direction of Prijedor there are (at least) three key terrains, which are important for both an attacker and a defender: south-west slopes of Kozara Mountain, Piskavica Mountain and Slavicka hills. The terrain configuration partly canalizes movement of mechanized units into two corridors: southern - approximately $8 \mathrm{~km}$ wide and northern -approximately $4 \mathrm{~km}$ wide. While there is one main road leading directly to Banja Luka from Prijedor, there is a large number of local roads that allow movement of mechanized units throughout the area with small restrictions. 
If there were real situation, this analysis would not be finished completely with this step. This is the first part of analysis, which is the base for complete IPB. For example, the next steps would include an analysis of critical points (bridges, tunnels, etc.), where important intersections (enemy movement in one or the other route can show us its intentions) are, where Mobility Corridors (enemy unit can pass through) are, Avenues of Approach (several MCs leading towards the same point), weather influence, Key Terrain (controlling it can bring significant advantage to the army under whose control it is), population, etc.

However, the aim of this project was to show one possible application of GIS in military terrain assessment. Therefore, the authors restricted the project only to one part of IPB process, plain terrain analysis. There are several points that must be accounted for when assessing reliability of this analysis. Firstly, there is a data reliability issue. The data has been downloaded from the Internet, and as an open source its reliability could be questionable. Secondly, accuracy of the data cannot also be assessed, as all the data comes from different sources. Finally, there have been constant changes related to the environment. New roads are built, new houses, water irrigation systems, etc. That is why data must be double checked, accurate and updated for the military use. IPB has to rely as much as possible on current reconnaissance and information collected by intelligence assets.

It has been confirmed that implementation of GIS in Military Terrain Assessment is possible and it contributes to IPB process. However, it greatly depends on the available data and experience and knowledge of military intelligence analyst, who performs it.

\section{Bibliography}

[1] Carl von Clausewitz, "On War", trans. COL James John Graham, N. Trübner, London, 1873

[2] CN-1681-INTRO-QGIS, "Introduction to Geospatial Technology Using QGIS", Canvas MOOC, 2015

[3] FM 1-02, "Operational Terms and Graphics", Headquarters Department of the Army, Washington DC, 2004

[4] FM 2-01.3,MCRP 2-3A, "Intelligence Preparation of the Battlefield/Battlespace", Headquarters Department of the Army, Washington DC, October 2009

[5] FM 34-130, "Intelligence Preparation of the Battlefield", Department of the Army, Washington DC, 1994

[6] FM 34-3, "Intelligence Analysis", Headquarters Department of the Army, Washington DC, July 2009

[7] Group of authors, "Rasprave o ratnoj veštini", VINC, Beograd, 1991

[8] Richard Bowyer, "Dictionary of Military Terms", third edition, A\&C Black, London

[9] Script, "Reference systems and cartographic representations", Geo Cell, EUFOR, 2008

[10] Sun Tzu, "The Art of War", Oxford University Press, New York and Oxford, 1963

[11] Verka Jovanović, "Geografski informacioni sistemi, Prvo izdanje", Univerzitet Singidunum Beograd i Univerzitet u Novom Sadu, Beograd, 2012 